\title{
Antifungal Resistance: Specific Focus on Multidrug Resistance in Candida auris and Secondary Azole Resistance in Aspergillus fumigatus
}

\author{
Sevtap Arikan-Akdagli ${ }^{1, *}$, Mahmoud Ghannoum ${ }^{2}$ and Jacques F. Meis ${ }^{3,4}$ \\ 1 Department of Medical Microbiology, Mycology Laboratory, Hacettepe University Medical School, \\ TR-06100 Ankara, Turkey \\ 2 Center for Medical Mycology, Department of Dermatology, University Hospitals Cleveland Medical Center, \\ Case Western Reserve University, Cleveland, OH 44106, USA; mag3@case.edu \\ 3 Department of Medical Microbiology and Infectious Diseases, Canisius Wilhelmina Hospital (CWZ), \\ 6532 Nijmegen, The Netherlands; jacques.meis@gmail.com \\ 4 Centre of Expertise in Mycology Radboudumc/CWZ, 6532 Nijmegen, The Netherlands \\ * Correspondence: sarikanakdagli@gmail.com
}

Received: 15 November 2018; Accepted: 3 December 2018; Published: 5 December 2018

\begin{abstract}
Antifungal resistance is a topic of concern, particularly for specific fungal species and drugs. Among these are the multidrug-resistant Candida auris and azole-resistant Aspergillus fumigatus. While the knowledge on molecular mechanisms of resistance is now accumulating, further data are also available for the clinical implications and the extent of correlation of in vitro resistance to clinical outcomes. This review article summarizes the epidemiology of $C$. auris infections, animal models focusing on the activity of novel antifungal compounds in C. auris infections, virulence factors, and the mechanisms of antifungal resistance for this multi-resistant Candida species. Regarding $A$. fumigatus, the significance of azoles in the treatment of $A$. fumigatus infections, reference methods available for the detection of resistance in vitro, molecular mechanisms of secondary azole resistance, routes of acquisition, and clinical implications of in vitro resistance are covered to provide guidance for the current status of azole resistance in A. fumigatus.
\end{abstract}

Keywords: Candida auris; Aspergillus fumigatus; antifungal resistance; multidrug resistance; mechanisms of antifungal resistance

\section{Candida auris}

\subsection{Epidemiology and Risk Factors for Candida auris Infection}

Nosocomial infections with resistant Candida species are increasing and candidemia is becoming a public health concern in Europe, the Americas, and Asia. This is associated with increasing numbers of immunocompromised individuals, the rampant empirical use of broad-spectrum antibiotics and fluconazole, and the widespread use of implanted medical devices. Invasive non-albicans candidiasis was mainly reported, until recently, due to C. glabrata, C. parapsilosis, C. tropicalis, and Pichia kudriavzevii (C. krusei). C. parapsilosis is common among newborns, while C. glabrata is more prevalent among older adults and patients with cancer. C. tropicalis, on the other hand, is more commonly seen in patients with leukemia and neutropenia. C. parapsilosis, a skin colonizer, is a common pathogen in intravascular catheter-related infections. Pichia kudriavzevii, in turn, is found more often among patients with leukemia and associated neutropenia, who receive fluconazole prophylaxis [1]. A new species, $C$. auris, associated with resistance to several antifungal drugs and difficulty in identification, has been observed to be emerging in the last decade. This yeast 
was first described in East Asia in 2009, after being isolated from a Japanese patient with otitis externa and three Korean patients with candidemia [2,3]. These observations did not attract much attention from the medical community at the time until clonal outbreaks were observed in several Indian hospitals [4,5]. Shortly after these seminal publications, reports followed from Kuwait, South Africa, and Venezuela [6-10]. C. auris, which was never heard of prior to the first publication in 2009 , became an emerging global health threat with outbreaks occurring in many health facilities. It is highly likely that C. auris was an underreported infection in the first years after 2009 due to difficulties in identification [11-16]. At present, infected and colonized patients have been identified in Australia [17], Austria [18], Belgium [19], Canada [20], China [21-23], Colombia [24,25], Egypt (unpublished), France [19], Germany [19], India [4,26-29], Iran (unpublished), Israel [30,31], Kenya [15], Kuwait [7,9,10], Korea [3,32], Malaysia [33], the Netherlands [15], Norway [19], Oman [34,35], Pakistan [36], Panama [37], Russia [15], Saudi Arabia [38], Singapore [39], South Africa [8,40], Spain [41], Switzerland [42], Thailand [15], United Kingdom [43-46], United States [36,47], United Arab Emirates [48], and Venezuela [6]. More than 4000 cases of infection and colonization, the majority from India and South Africa, have been recorded to date, but it is highly likely that we are observing only the tip of the iceberg.

C. auris is a novel Candida species in the Candida haemulonii species complex, which causes a wide range of infections, especially in debilitated patients residing in intensive care units (ICUs). A large 18-month prospective study in Indian ICUs recorded 1400 candidemia cases; C. auris was identified as the fifth most common cause found in 19 out of 27 ICUs, with a prevalence of $5.3 \%$ [27]. In some tertiary care Indian hospitals, $C$. auris is the second most common cause of candidemia after $C$. tropicalis [49]. A tertiary medical center in South America reported C. auris as the sixth most common cause of nosocomial bloodstream infections between March 2012 and July 2013 [6]. The mode of spread within the hospital setting is through person to person transmission and via contaminated surfaces and/or equipment. During outbreaks, C. auris can contaminate the room of colonized or infected patients [50]. It is therefore of utmost importance to quickly identify contaminated surfaces and screen specimens of patients. Real-time detection and identification of $C$. auris is the target of several molecular kits [51-59]. The survival of $C$. auris for weeks, even months, within the hospital confirms the importance of infection prevention programs [60-62]. Transmission from patient to patient has been documented to lead to skin colonization by $C$. auris and increased risk for candidemia. The hospital environment represents a reservoir that contributes to the nosocomial transmission of C. auris similar to that seen with multi-resistant bacterial pathogens $[63,64]$. Risk factors for infection with $C$. auris are related to immunosuppression, hospitalization in intensive care units over prolonged periods, use of central venous and urinary catheters, and empirical use of antibiotics or antifungals. Adults are mainly affected, but in an outbreak situation in Venezuela 13/18 cases were pediatric patients [6]. As observed in many other studies, all isolates were initially mis-identified as Candida haemulonii, a commonly reported mistake [65-67]. Sequencing of the internal transcribed spacer (ITS) region and MALDI-TOF analysis were necessary to identify isolates of the outbreak involved as $C$. auris. The predisposing risk factors for $C$. auris infection are similar to other opportunistic Candida species [1]; that is, immunocompromised patients (diabetes mellitus, malignancy, chronic renal disease, neutropenia, HIV), concomitant bacteremia, broad spectrum antibacterial or antifungal therapy within 90 days, surgery within 90 days, presence of central venous catheters or urinary catheters, ICU stay, and parenteral nutrition (PN) administration confer an increased risk of acquiring C. auris. A case-control study in an Indian center was conducted to determine specific risk factors predisposing to $C$. auris candidemia [29]. Patients with $C$. auris $(n=74)$ and non-auris $(n=1087)$ fungemia cases were analyzed. Multivariate analysis showed that patients with respiratory diseases, vascular surgery, and prolonged exposure to fluconazole were more likely to develop ICU-onset $C$. auris fungemia. In describing the epidemiology of C. auris infections, the Center for Disease Control (CDC) used whole genome sequencing of 54 isolates collected from India, Pakistan, South Africa, Japan, and Venezuela [36]. Four distinct geographical clades were observed, suggesting emergence at the same 
time on three continents. Similar geographic clustering was observed with Amplified Fragment Length Polymorphism(AFLP) and proteomic analysis of $C$. auris isolates from three different continents-Asia, Africa, and Latin America [68]. A recent Whole Genome Sequencing (WGS) and single-nucleotide polymorphism (SNP) analysis of $C$. auris strains isolated in the USA showed multiple introductions of $C$. auris isolates belonging to the four clades, and spread among healthcare facilities [47]. Most C. auris strains $(>60-90 \%)$ are resistant to fluconazole, $10-30 \%$ exhibit a high minimum inhibitory concentration (MIC) for amphotericin $\mathrm{B}$, and $<5 \%$ can be considered resistant to echinocandins $[28,69]$. Given the recent unprecedented worldwide spread and multidrug resistance, C. auris is included in the world's 10 most feared fungi [70].

\subsection{Virulence Factors of $C$. auris}

To determine the virulence properties of $C$. auris relative to $C$. albicans, a set of clinical strains were investigated regarding the ability to germinate, adhere, and produce extracellular enzymes [71]. C. auris strains failed to germinate but, in contrast and as expected, C. albicans germinated profusely. Similarly, C. auris exhibited a significantly reduced ability to adhere to silicon elastomer disks relative to C. albicans. Moreover, the $C$. auris isolates produced phospholipase and proteinase in a strain-dependent manner (37.5\% of the $C$. auris strains possessed phospholipase activity, while $64 \%$ evaluated secreted proteinase activity). The last virulence factor evaluated was the ability of $C$. auris to form biofilms. Our data showed that the formed biofilms were mainly composed of yeast cells, while biofilms formed by $C$. albicans had a heterogeneous architecture of biofilms comprised of yeast and hyphae morphology embedded within the extracellular matrix. Furthermore, C. auris biofilms had a limited amount of extracellular matrix relative to $C$. albicans and its biofilm thickness was significantly less than the biofilms formed by $C$. albicans. Taken together, these data show that $C$. auris is relatively less pathogenic than C. albicans.

\subsection{C. auris Animal Models and Activity of Experimental Antifungals}

To gain insight into the in vivo virulence of $C$. auris, an immunosuppressed murine model was developed [72,73]. Once the model was established it was used to evaluate the efficacy of two experimental antifungals (rezafungin and APX001A). The data showed that rezafungin had a significantly reduced CFUs/g kidneys fungal burden compared with vehicle- or amphotericin B-treated groups. Furthermore, treatment with rezafungin resulted in a significantly lower CFUs/g tissue fungal burden compared to micafungin-treated animals [72].

Evaluation of the efficacy of APX001 using the optimized immunocompromised mouse model showed that treatment with this experimental drug resulted in a significant increase in animal survival (between 80 and 100\% survival in the three treatment groups). In contrast, treatment with anidulafungin led to only a 50\% survival rate. In addition, APX001 treatment led to a significant reduction in CFUs/g of kidneys, lung, and brain tissue compared to the vehicle-treated group [73]. In an immunocompetent murine model, virulence was also highest for $C$. albicans, closely followed by C. auris, C. glabrata, and C. haemulonii, respectively [74].

\subsection{Resistance of C. auris}

Besides being antifungal-resistant, C. auris is thermotolerant, grows well up to $42{ }^{\circ} \mathrm{C}$, and is salt-tolerant (up to $10 \%$ ). These characteristics can be used to design selective media for the detection of $C$. auris for screening purposes which have been used successfully in outbreak investigations [75]. Concerning resistance to antifungal agents, $C$. auris has demonstrated extensive resistance to azoles and amphotericin B $[24,28]$. The ATP-binding cassette $(A B C)$ transporter activity was significantly higher in C. auris than in C. glabrata [31]. Several genes show encoding of ABC transporters and the important families of $C$. auris major facilitator superfamily (MFS) genes [76]. An Indian study with a large number of isolates showed that $41 \%$ of $C$. auris from India showed resistance to two antifungal classes and $4 \%$ to three antifungal agents [28]. Molecular mechanisms responsible for antifungal 
resistance point to efflux pumps and mutations in the lanosterol 14-alpha-demethylase (ERG11) gene to explain the high rate of resistance to fluconazole [28,31]. The latter study demonstrated that $90 \%$ of C. auris isolates were resistant to fluconazole (MICs 32 to $\geq 64 \mathrm{mg} / \mathrm{L}$ ). ERG11 sequences of resistant C. auris exhibited substitutions of the Y132 and K143 amino acids in 77\% of the fluconazole-resistant strains. No substitutions at these positions were observed in isolates with low fluconazole MICs (1-2 $\mathrm{mg} / \mathrm{L})$, suggesting that these substitutions confer the fluconazole resistance phenotype similar to that described for C. albicans [77].

Another study, in a murine model, showed that micafungin was superior compared to fluconazole or amphotericin B, with greater fungicidal activity [78]. These findings make echinocandins the drugs of choice to treat $C$. auris infections and clinical trials are on their way to explore the therapeutic potential of new drugs.

The combination of antifungals such as voriconazole and echinocandins has been shown to be promising in vitro against resistant $C$. auris [79]. Although some studies show variable susceptibility of C. auris to the echinocandin class [80], the good news is that there are new drugs in development with excellent activity against $C$. auris [71-73,81-85]. SCY-078, a novel orally bioavailable 1,3- $\beta$-D-glucan synthesis inhibitor, has been shown to exhibit both in vitro and in vivo activity against $C$. auris, including some echinocandin-resistant isolates. VT-1598 is another new azole drug with broad activity including C. auris isolates (MIC range $0.03-8 \mathrm{mg} / \mathrm{L}$ ) [86,87].

The cleaning and terminal disinfection of rooms where $C$. auris-colonized patients have been problematic [61,88]. Moore et al. [89] showed that chlorine-based disinfectants and iodine-based skin antiseptics were effective against $C$. auris and reduced environmental contamination and skin colonization. Chlorhexidine-based products may also be effective. Abdolrasouli and collaborators [90] demonstrated that $C$. auris isolates were inhibited by chlorhexidine gluconate at $0.125-1.5 \%$ and by iodinated povidone at a concentration of $0.07-1.25 \%$.

\section{Aspergillus fumigatus}

\subsection{Azole Resistance in A. fumigatus}

Aspergillus remains significant as one of the causative agents of invasive infections in immunocompromised individuals and frequently constitutes the most common mold genus isolated in this setting. While voriconazole is the primary drug of choice in the treatment of invasive aspergillosis, the emergence of azole resistance in Aspergillus has been a concern since the first report of secondary resistance of A. fumigatus to itraconazole in 1997 [91,92]. Antifungal drugs which exert activity against Aspergillus spp. are amphotericin B, triazoles, and echinocandins. Furthermore, triazoles are of particular significance due to the availability of oral formulations. Based on this, triazoles constitute significant therapeutic options for patients with chronic pulmonary aspergillosis and allergic bronchopulmonary aspergillosis who require long-term therapy [93] and azole resistance in A. fumigatus is thus a concern in this respect as well.

Secondary azole resistance in A. fumigatus has been reported from many countries and centers in six continents at extensively varying rates. Similar to those for strains isolated from clinical samples, resistance rates detected for environmental strains are also diverse [94-101]. The ISHAM/ECMM Aspergillus Resistance Surveillance Working Group aims to facilitate surveillance studies to determine resistance epidemiology in countries where data are currently lacking and provide further insight in terms of clinical implications [102].

While secondary azole resistance in A. fumigatus draws remarkable attention, the awareness and knowledge on primary antifungal resistance in Aspergillus strains are also increasing. Among the species which are relatively common causes of invasive infections and exhibit primary resistance or reduced susceptibility to one or more antifungal drugs are Aspergillus lentulus (resistance to azoles and amphotericin B and varied susceptibility to caspofungin), Aspergillus flavus (reduced susceptibility to 
amphotericin B and varied susceptibility to caspofungin), Aspergillus alliaceus (reduced susceptibility to amphotericin B and caspofungin), and Aspergillus terreus (resistance to amphotericin B) [96].

\subsection{Detection of Antifungal Resistance In Vitro by Reference Methods}

Reference CLSI [103] and EUCAST [104,105] microdilution susceptibility testing methods are available for testing antifungal drugs against Aspergillus and recommended for routine use [106,107]. A disk diffusion method of CLSI for testing non-dermatophyte molds and thus applying also to Aspergillus is also available [108]. Epidemiological cut-off values have been determined for the interpretation of the results obtained by the CLSI method [109-112], while both epidemiological cut-off values and clinical breakpoints are available for interpreting EUCAST minimum inhibitory concentration values (MIC, $\mathrm{mg} / \mathrm{L}$ ) for some drugs and species [113]. The official reading method for amphotericin B and azole MICs against Aspergillus is visual reading for both CLSI and EUCAST methodologies. A spectrophotometric reading alternative for EUCAST amphotericin B and azole MICs at $5 \%$ growth cut-off (vs. complete inhibition of growth visually) proved to be a reliable alternative [105].

An agar screening method for the detection of secondary azole resistance in A. fumigatus strains has also been validated recently by a multicenter study undertaken by EUCAST [114]. This method uses (in-house or commercially available) 4 -well agar plates containing itraconazole $(4 \mathrm{mg} / \mathrm{L})$, voriconazole $(2 \mathrm{mg} / \mathrm{L})$, and posaconazole $(0.5 \mathrm{mg} / \mathrm{L})$; the fourth well serves as the growth control well without any antifungal drug. The ranges of $80-100 \%$ and $97-100 \%$ were obtained, respectively, for interobserver agreement rate and overall sensitivity. The inter-plate (in-house vs. commercial) agreement rate was high. Similarly, the sensitivity for simulated mixed samples of wild-type and mutant strains and the overall specificity rates also proved to be acceptably high (83-100\% and $95-100 \%$, respectively). Based on these data, the assay was validated and is now available as a reference method as documented in EUCAST E.DEF 10.1 [115]. It is an easy and reliable method recommended to be used for routine laboratory work-up, to be followed by reference MIC testing for confirmation in case of the detection of a resistant strain [106].

\subsection{Molecular Mechanisms Involved in Secondary Azole Resistance and the Resulting Azole Susceptibility Profiles}

Point mutations in the cyp51A gene associated with amino acid changes of M220, G54, G138, $\mathrm{G} 448 \mathrm{~S}$, as well as $\mathrm{L} 98 \mathrm{H}$ are the most common mechanisms of secondary azole resistance in A. fumigatus. Extra copies of the cyp51A gene (e.g., tandem repeats of a 34- or 46-bp sequence in the promoter of the cyp51A gene) may also accompany specific amino acid changes. The typical examples of this combined pattern are TR34/L98H and TR46/Y121F/T289A [116]. A tandem repeat of 53 bp without any accompanying amino acid change has also been described $[117,118]$. In addition, non-cyp51 mutations and increased expression of efflux pumps may play a role in the development of secondary azole resistance. On the other hand, the mechanism remains unknown for a number of isolates. The expected azole susceptibility profiles in relation to the associated amino acid changes and/or tandem repeats are summarized in Table $1[95,116]$.

Table 1. Expected azole susceptibility profiles with respect to the detected resistance mechanism(s).

\begin{tabular}{lccc}
\hline \multicolumn{1}{c}{$\begin{array}{c}\text { Associated Amino Acid } \\
\text { Change/Tandem Repeat }\end{array}$} & Resistance & Reduced Susceptibility & Variable Susceptibility Profile \\
\hline G54 & ITC, POS & & \\
G138 & ITC, POS & & \\
G448S & VRC & ITC, POS & POS \\
M220 & ITC & VRC & ITC, POS \\
TR34/L98H * & ITC, VRC, POS, ISV & & \\
TR46/Y121F/T289A & VRC & POS & \\
TR53 & ITC, VRC & Isolates with
\end{tabular}

ISV: isavuconazole; ITC: itraconazole; POS: posaconazole; VRC: voriconazole; *: Isolates with TR34/L98H/S297T/F495I changes may have lower minimum inhibitory concentrations (MICs) of voriconazole in the wild-type range. The S297T mutation might be a compensatory mutation in these cases $[119,120]$. 


\subsection{Acquisition of Secondary Azole Resistance}

There are two mechanisms that play a role in the development of secondary azole resistance in A. fumigatus. First is the (long-term) azole therapy in an individual patient with chronic pulmonary lung disease mostly in existence of a pulmonary cavity, and second is the direct acquisition of a resistant strain from the environment. The latter develops due to the use of azole fungicides (penconazole, difenoconazole, tetraconazole, and tebuconazole) in the environment in agriculture for plant protection $[98,121]$. The molecular mechanisms leading to resistance also differ in general for these two routes of acquisition. In the patient-acquired route, M220, G54, and G138 changes are more common while TR34/L98H and TR46/Y121F/T289A patterns are mostly (but not always) observed following environmental acquisition $[95,116]$.

\subsection{Clinical Implications and Current Recommendations for Treatment of Aspergillosis due to Azole-Resistant} A. fumigatus

While high azole MICs [122,123] or the existence of cyp51A mutations [124] were found to be correlated with clinical failure in some studies, other investigators were not able to detect any correlation between MICs and survival rates [125]. This may also emphasize the influence of host factors as well as several others on clinical outcomes in invasive fungal infections observed in immunocompromised individuals. The low rates of resistance, i.e., the low number of infections due to azole-resistant strains included in the analysis, may also render it more difficult to detect any possibly existing in vitro-in vivo correlation. "Strong" or "Moderate" recommendations for the treatment of documented azole-resistant aspergillosis, as included in the recently published ESCMID-ECMM-ERS Guideline [106], are liposomal amphotericin B monotherapy (Strength of Recommendation (SoR) and Quality of Evidence (QoE): AIIu) and voriconazole and anidulafungin combination (BIII), respectively. Other options with a "Marginal" level of recommendation (CIII for all noted alternatives) include amphotericin B lipid complex monotherapy, posaconazole and caspofungin combination, caspofungin or micafungin monotherapy. The expert opinion, on the other hand, recommends a modification in primary therapeutic choice of voriconazole in case of local environmental resistance rates of $>10 \%$. Voriconazole and echinocandin combination or liposomal amphotericin B monotherapy is recommended for initial therapy under these settings [126].

\section{Concluding Remark}

The emerging field of molecular mechanisms of antifungal resistance has been an underestimated area of global public health concern, but significant progress has been made lately in A. fumigatus and C. auris, although research challenges remain formidable.

Author Contributions: S.A.-A., M.G. and J.F.M. prepared the manuscript.

Funding: This research received no external funding.

Conflicts of Interest: JFM reports grants from F2G, Merck and Pulmozyme, consultancy fees from Scynexis and speaker fees from Merck, United Medical, Gilead Sciences and TEVA, outside the submitted work. MAG declares receiving grants, and/or acting as a consultant for the following companies: Scynexis, Amplyx, Cidara, and F2G. SAA reports investigator-initiated research grant from Pfizer and lecture honoraria from Astellas, Gilead, Merck, and Pfizer, outside the submitted work.

\section{References}

1. Pappas, P.G.; Lionakis, M.S.; Arendrup, M.C.; Ostrosky-Zeichner, L.; Kullberg, B.J. Invasive candidiasis. Nat. Rev. Dis. Primers 2018, 4, 18026. [CrossRef] [PubMed]

2. Satoh, K.; Makimura, K.; Hasumi, Y.; Nishiyama, Y.; Uchida, K.; Yamaguchi, H. Candida auris sp. nov., a novel ascomycetous yeast isolated from the external ear canal of an inpatient in a Japanese hospital. Microbiol. Immunol. 2009, 53, 41-44. [CrossRef] [PubMed]

3. Lee, W.G.; Shin, J.H.; Uh, Y.; Kang, M.G.; Kim, S.H.; Park, K.H.; Jang, H.C. First three reported cases of nosocomial fungemia caused by Candida auris. J. Clin. Microbiol. 2011, 49, 3139-3142. [CrossRef] [PubMed] 
4. Chowdhary, A.; Sharma, C.; Duggal, S.; Agarwal, K.; Prakash, A.; Singh, P.K.; Jain, S.; Kathuria, S.; Randhawa, H.S.; Hagen, F.; et al. New clonal strain of Candida auris, Delhi, India. Emerg. Infect. Dis. 2013, 19, 1670-1673. [CrossRef] [PubMed]

5. Chowdhary, A.; Sharma, C.; Meis, J.F. Candida auris: A rapidly emerging cause of hospital-acquired multidrug-resistant fungal infections globally. PLoS Pathog. 2017, 13, e1006290. [CrossRef] [PubMed]

6. Calvo, B.; Melo, A.S.; Perozo-Mena, A.; Hernandez, M.; Francisco, E.C.; Hagen, F.; Meis, J.F.; Colombo, A.L. First report of Candida auris in America: Clinical and microbiological aspects of 18 episodes of candidemia. J. Infect. 2016, 73, 369-374. [CrossRef] [PubMed]

7. Emara, M.; Ahmad, S.; Khan, Z.; Joseph, L.; Al-Obaid, I.; Purohit, P.; Bafna, R. Candida auris candidemia in Kuwait, 2014. Emerg. Infect. Dis. 2015, 21, 1091-1092. [CrossRef]

8. Magobo, R.E.; Corcoran, C.; Seetharam, S.; Govender, N.P. Candida auris-associated candidemia, South Africa. Emerg. Infect. Dis. 2014, 20, 1250-1251. [CrossRef]

9. Khan, Z.; Ahmad, S.; Al-Sweih, N.; Joseph, L.; Alfouzan, W.; Asadzadeh, M. Increasing prevalence, molecular characterization and antifungal drug susceptibility of serial Candida auris isolates in Kuwait. PLoS ONE 2018, 13, e0195743. [CrossRef]

10. Khan, Z.; Ahmad, S.; Benwan, K.; Purohit, P.; Al-Obaid, I.; Bafna, R.; Emara, M.; Mokaddas, E.; Abdullah, A.A.; Al-Obaid, K.; et al. Invasive Candida auris infections in Kuwait hospitals: epidemiology, antifungal treatment and outcome. Infection 2018, 46, 641-650. [CrossRef]

11. Bidaud, A.L.; Chowdhary, A.; Dannaoui, E. Candida auris: An emerging drug resistant yeast-A mini-review. J. Mycol Med. 2018, 28, 568-573. [CrossRef] [PubMed]

12. Clancy, C.J.; Nguyen, M.H. Emergence of Candida auris: An international call to arms. Clin. Infect. Dis. 2017, 64, 141-143. [CrossRef] [PubMed]

13. Forsberg, K.; Woodworth, K.; Walters, M.; Berkow, E.L.; Jackson, B.; Chiller, T.; Vallabhaneni, S. Candida auris: The recent emergence of a multidrug-resistant fungal pathogen. Med. Mycol. 2018. [CrossRef] [PubMed]

14. Jeffery-Smith, A.; Taori, S.K.; Schelenz, S.; Jeffery, K.; Johnson, E.M.; Borman, A.; Candida auris Incident Management, T.; Manuel, R.; Brown, C.S. Candida auris: a Review of the literature. Clin. Microbiol. Rev. 2018, 31, e0029-17. [CrossRef] [PubMed]

15. Saris, K.; Meis, J.F.; Voss, A. Candida auris. Curr Opin Infect. Dis. 2018, 31, 334-340. [CrossRef] [PubMed]

16. Tsay, S.; Kallen, A.; Jackson, B.R.; Chiller, T.M.; Vallabhaneni, S. Approach to the investigation and management of patients with Candida auris, an emerging multidrug-resistant yeast. Clin. Infect. Dis. 2018, 66, 306-311. [CrossRef]

17. Heath, C.H.; Dyer, J.R.; Pang, S.; Coombs, G.W.; Gardam, D.J. Candida auris sternal osteomyelitis diagnosis in man from Kenya visiting Australia, 2015. Emerg. Infect. Dis. 2019, 25. (in press).

18. Pekard-Amenitsch, S.; Schriebl, A.; Posawetz, W.; Willinger, B.; Kolli, B.; Buzina, W. Isolation of Candida auris from Ear of Otherwise Healthy Patient, Austria, 2018. Emerg. Infect. Dis. 2018, 24, 1596-1597. [CrossRef]

19. Kohlenberg, A.; Struelens, M.J.; Monnet, D.L.; Plachouras, D.; The Candida Auris Survey Collaborative, G. Candida auris: epidemiological situation, laboratory capacity and preparedness in European Union and European Economic Area countries, 2013 to 2017. Euro Surveill 2018, 23. [CrossRef]

20. Schwartz, I.S.; Hammond, G.W. First reported case of multidrug-resistant Candida auris in Canada. Can. Commun Dis. Rep. 2017, 43, 150-153. [CrossRef]

21. Chen, Y.; Zhao, J.; Han, L.; Qi, L.; Fan, W.; Liu, J.; Wang, Z.; Xia, X.; Chen, J.; Zhang, L. Emergency of fungemia cases caused by fluconazole-resistant Candida auris in Beijing, China. J. Infect. 2018. [CrossRef]

22. Tian, S.; Rong, C.; Nian, H.; Li, F.; Chu, Y.; Cheng, S.; Shang, H. First cases and risk factors of super yeast Candida auris infection or colonization from Shenyang, China. Emerg. Microbes Infect. 2018, 7, 128. [CrossRef] [PubMed]

23. Wang, X.; Bing, J.; Zheng, Q.; Zhang, F.; Liu, J.; Yue, H.; Tao, L.; Du, H.; Wang, Y.; Wang, H.; et al. The first isolate of Candida auris in China: clinical and biological aspects. Emerg. Microbes Infect. 2018, 7, 93. [CrossRef] [PubMed]

24. Escandon, P.; Chow, N.A.; Caceres, D.H.; Gade, L.; Berkow, E.L.; Armstrong, P.; Rivera, S.; Misas, E.; Duarte, C.; Moulton-Meissner, H.; et al. Molecular epidemiology of Candida auris in Colombia reveals a highly-related, country-wide colonization with regional patterns in Amphotericin B resistance. Clin. Infect. Dis. 2018. [CrossRef] [PubMed] 
25. Morales-Lopez, S.E.; Parra-Giraldo, C.M.; Ceballos-Garzon, A.; Martinez, H.P.; Rodriguez, G.J.; Alvarez-Moreno, C.A.; Rodriguez, J.Y. Invasive infections with multidrug-resistant yeast Candida auris, Colombia. Emerg. Infect. Dis. 2017, 23, 162-164. [CrossRef] [PubMed]

26. Biswal, M.; Rudramurthy, S.M.; Jain, N.; Shamanth, A.S.; Sharma, D.; Jain, K.; Yaddanapudi, L.N.; Chakrabarti, A. Controlling a possible outbreak of Candida auris infection: lessons learnt from multiple interventions. J. Hosp. Infect. 2017, 97, 363-370. [CrossRef] [PubMed]

27. Chakrabarti, A.; Sood, P.; Rudramurthy, S.M.; Chen, S.; Kaur, H.; Capoor, M.; Chhina, D.; Rao, R.; Eshwara, V.K.; Xess, I.; et al. Incidence, characteristics and outcome of ICU-acquired candidemia in India. Intensive Care Med. 2015, 41, 285-295. [CrossRef] [PubMed]

28. Chowdhary, A.; Prakash, A.; Sharma, C.; Kordalewska, M.; Kumar, A.; Sarma, S.; Tarai, B.; Singh, A.; Upadhyaya, G.; Upadhyay, S.; et al. A multicentre study of antifungal susceptibility patterns among 350 Candida auris isolates (2009-17) in India: role of the ERG11 and FKS1 genes in azole and echinocandin resistance. J. Antimicrob. Chemother. 2018, 73, 891-899. [CrossRef]

29. Rudramurthy, S.M.; Chakrabarti, A.; Paul, R.A.; Sood, P.; Kaur, H.; Capoor, M.R.; Kindo, A.J.; Marak, R.S.K.; Arora, A.; Sardana, R.; et al. Candida auris candidaemia in Indian ICUs: analysis of risk factors. J. Antimicrob. Chemother. 2017, 72, 1794-1801. [CrossRef]

30. Belkin, A.; Gazit, Z.; Keller, N.; Ben-Ami, R.; Wieder-Finesod, A.; Novikov, A.; Rahav, G.; Brosh-Nissimov, T. Candida auris infection leading to nosocomial transmission, Israel, 2017. Emerg. Infect. Dis. 2018, 24, 801-804. [CrossRef]

31. Ben-Ami, R.; Berman, J.; Novikov, A.; Bash, E.; Shachor-Meyouhas, Y.; Zakin, S.; Maor, Y.; Tarabia, J.; Schechner, V.; Adler, A.; et al. Multidrug-resistant Candida haemulonii and Candida auris, Tel Aviv, Israel. Emerg. Infect. Dis. 2017, 23. [CrossRef]

32. Choi, H.I.; An, J.; Hwang, J.J.; Moon, S.Y.; Son, J.S. Otomastoiditis caused by Candida auris: Case report and literature review. Mycoses 2017, 60, 488-492. [CrossRef] [PubMed]

33. Mohd Tap, R.; Lim, T.C.; Kamarudin, N.A.; Ginsapu, S.J.; Abd Razak, M.F.; Ahmad, N.; Amran, F. A fatal case of Candida auris and Candida tropicalis candidemia in neutropenic patient. Mycopathologia 2018, 183, 559-564. [CrossRef]

34. Al-Siyabi, T.; Al Busaidi, I.; Balkhair, A.; Al-Muharrmi, Z.; Al-Salti, M.; Al'Adawi, B. First report of Candida auris in Oman: Clinical and microbiological description of five candidemia cases. J. Infect. 2017, 75, 373-376. [CrossRef] [PubMed]

35. Mohsin, J.; Hagen, F.; Al-Balushi, Z.A.M.; de Hoog, G.S.; Chowdhary, A.; Meis, J.F.; Al-Hatmi, A.M.S. The first cases of Candida auris candidaemia in Oman. Mycoses 2017, 60, 569-575. [CrossRef] [PubMed]

36. Lockhart, S.R.; Etienne, K.A.; Vallabhaneni, S.; Farooqi, J.; Chowdhary, A.; Govender, N.P.; Colombo, A.L.; Calvo, B.; Cuomo, C.A.; Desjardins, C.A.; et al. Simultaneous emergence of multidrug-resistant Candida auris on three continents confirmed by whole-genome sequencing and epidemiological analyses. Clin. Infect. Dis. 2017, 64, 134-140. [CrossRef] [PubMed]

37. Araúz, A.B.; Caceres, D.H.; Santiago, E.; Armstrong, P.; Arosemena, S.; Ramos, C.; Espinosa-Bode, A.; Borace, J.; Hayer, L.; Cedeno, I.; et al. Isolation of Candida auris from nine patients in Central America: Importance of accurate diagnosis and susceptibility testing. Mycoses 2018, 61, 44-47. [CrossRef] [PubMed]

38. Abdalhamid, B.; Almaghrabi, R.; Althawadi, S.; Omrani, A. First report of Candida auris infections from Saudi Arabia. J. Infect. Public Health 2018, 11, 598-599. [CrossRef] [PubMed]

39. Tan, Y.E.; Tan, A.L. Arrival of Candida auris fungus in Singapore: Report of the first three cases. Ann. Acad Med. Singapore 2018, 47, 260-262.

40. Govender, N.P.; Magobo, R.E.; Mpembe, R.; Mhlanga, M.; Matlapeng, P.; Corcoran, C.; Govind, C.; Lowman, W.; Senekal, M.; Thomas, J. Candida auris in South Africa, 2012-2016. Emerg. Infect. Dis. 2018, 24, 2036-2040. [CrossRef]

41. Ruiz-Gaitan, A.; Moret, A.M.; Tasias-Pitarch, M.; Aleixandre-Lopez, A.I.; Martinez-Morel, H.; Calabuig, E.; Salavert-Lleti, M.; Ramirez, P.; Lopez-Hontangas, J.L.; Hagen, F.; et al. An outbreak due to Candida auris with prolonged colonisation and candidaemia in a tertiary care European hospital. Mycoses 2018, 61, 498-505. [CrossRef]

42. Riat, A.; Neofytos, D.; Coste, A.; Harbarth, S.; Bizzini, A.; Grandbastien, B.; Pugin, J.; Lamoth, F. First case of Candida auris in Switzerland: discussion about preventive strategies. Swiss Med. Wkly. 2018, 148, w14622. [PubMed] 
43. Borman, A.M.; Szekely, A.; Johnson, E.M. Comparative pathogenicity of United Kingdom isolates of the emerging pathogen Candida auris and other key pathogenic Candida species. mSphere 2016, 1. [CrossRef] [PubMed]

44. Schelenz, S.; Hagen, F.; Rhodes, J.L.; Abdolrasouli, A.; Chowdhary, A.; Hall, A.; Ryan, L.; Shackleton, J.; Trimlett, R.; Meis, J.F.; et al. First hospital outbreak of the globally emerging Candida auris in a European hospital. Antimicrob. Resist. Infect. Control. 2016, 5, 35. [CrossRef] [PubMed]

45. Eyre, D.W.; Sheppard, A.E.; Madder, H.; Moir, I.; Moroney, R.; Quan, T.P.; Griffiths, D.; George, S.; Butcher, L.; Morgan, M.; et al. A Candida auris outbreak and its Control in an intensive care setting. N. Engl. J. Med. 2018, 379, 1322-1331. [CrossRef] [PubMed]

46. Rhodes, J.; Abdolrasouli, A.; Farrer, R.A.; Cuomo, C.A.; Aanensen, D.M.; Armstrong-James, D.; Fisher, M.C.; Schelenz, S. Genomic epidemiology of the UK outbreak of the emerging human fungal pathogen Candida auris. Emerg. Microbes Infect. 2018, 7, 43. [CrossRef] [PubMed]

47. Chow, N.A.; Gade, L.; Tsay, S.V.; Forsberg, K.; Greenko, J.A.; Southwick, K.L.; Barrett, P.M.; Kerins, J.L.; Lockhart, S.R.; Chiller, T.M.; et al. Multiple introductions and subsequent transmission of multidrug-resistant Candida auris in the USA: a molecular epidemiological survey. Lancet Infect. Dis. 2018, 18, 1377-1384. [CrossRef]

48. Alatoom, A.; Sartawi, M.; Lawlor, K.; AbdelWareth, L.; Thomsen, J.; Nusair, A.; Mirza, I. Persistent candidemia despite appropriate fungal therapy: First case of Candida auris from the United Arab Emirates. Int. J. Infect. Dis. 2018, 70, 36-37. [CrossRef] [PubMed]

49. Mathur, P.; Hasan, F.; Singh, P.K.; Malhotra, R.; Walia, K.; Chowdhary, A. Five-year profile of candidaemia at an Indian trauma centre: High rates of Candida auris blood stream infections. Mycoses 2018. [CrossRef] [PubMed]

50. Piedrahita, C.T.; Cadnum, J.L.; Jencson, A.L.; Shaikh, A.A.; Ghannoum, M.A.; Donskey, C.J. Environmental surfaces in healthcare facilities are a potential source for transmission of Candida auris and other Candida species. Infect. Control. Hosp. Epidemiol. 2017, 38, 1107-1109. [CrossRef] [PubMed]

51. Yamamoto, M.; Alshahni, M.M.; Tamura, T.; Satoh, K.; Iguchi, S.; Kikuchi, K.; Mimaki, M.; Makimura, K. Rapid detection of Candida auris based on loop-mediated isothermal amplification (LAMP). J. Clin. Microbiol. 2018, 56. [CrossRef]

52. Kordalewska, M.; Zhao, Y.; Lockhart, S.R.; Chowdhary, A.; Berrio, I.; Perlin, D.S. Rapid and accurate molecular identification of the emerging multidrug-resistant pathogen Candida auris. J. Clin. Microbiol. 2017, 55, 2445-2452. [CrossRef] [PubMed]

53. Leach, L.; Zhu, Y.; Chaturvedi, S. Development and validation of a real-time PCR assay for rapid detection of Candida auris from surveillance samples. J. Clin. Microbiol. 2018, 56. [CrossRef] [PubMed]

54. Martinez-Murcia, A.; Navarro, A.; Bru, G.; Chowdhary, A.; Hagen, F.; Meis, J.F. Internal validation of GPS() MONODOSE CanAur dtec-qPCR kit following the UNE/EN ISO/IEC 17025:2005 for detection of the emerging yeast Candida auris. Mycoses 2018, 61, 877-884. [CrossRef] [PubMed]

55. Ruiz-Gaitan, A.C.; Fernandez-Pereira, J.; Valentin, E.; Tormo-Mas, M.A.; Eraso, E.; Peman, J.; de Groot, P.W.J. Molecular identification of Candida auris by PCR amplification of species-specific GPI protein-encoding genes. Int. J. Med. Microbiol. 2018, 308, 812-818. [CrossRef] [PubMed]

56. Sexton, D.J.; Kordalewska, M.; Bentz, M.L.; Welsh, R.M.; Perlin, D.S.; Litvintseva, A.P. Direct detection of emergent fungal pathogen Candida auris in clinical skin swabs by SYBR Green qPCR assay. J. Clin. Microbiol. 2018. [CrossRef] [PubMed]

57. Sexton, D.J.; Bentz, M.L.; Welsh, R.M.; Litvintseva, A.P. Evaluation of a new T2 Magnetic Resonance assay for rapid detection of emergent fungal pathogen Candida auris on clinical skin swab samples. Mycoses 2018, 61, 786-790. [CrossRef] [PubMed]

58. Theill, L.; Dudiuk, C.; Morales-Lopez, S.; Berrio, I.; Rodriguez, J.Y.; Marin, A.; Gamarra, S.; Garcia-Effron, G. Single-tube classical PCR for Candida auris and Candida haemulonii identification. Rev. Iberoam Micol. 2018, 35, 110-112. [CrossRef] [PubMed]

59. Hou, X.; Lee, A.; Jimenez-Ortigosa, C.; Kordalewska, M.; Perlin, D.S.; Zhao, Y. Rapid detection of ERG11-associated azole resistance and FKS-associated echinocandin resistance in Candida auris. Antimicrob. Agents Chemother. 2018. [CrossRef] 
60. Cadnum, J.L.; Shaikh, A.A.; Piedrahita, C.T.; Jencson, A.L.; Larkin, E.L.; Ghannoum, M.A.; Donskey, C.J. Relative resistance of the emerging fungal pathogen Candida auris and other Candida species to killing by ultraviolet light. Infect. Control. Hosp. Epidemiol 2018, 39, 94-96. [CrossRef]

61. Kean, R.; Sherry, L.; Townsend, E.; McKloud, E.; Short, B.; Akinbobola, A.; Mackay, W.G.; Williams, C.; Jones, B.L.; Ramage, G. Surface disinfection challenges for Candida auris: an in-vitro study. J. Hosp. Infect. 2018, 98, 433-436. [CrossRef]

62. Welsh, R.M.; Bentz, M.L.; Shams, A.; Houston, H.; Lyons, A.; Rose, L.J.; Litvintseva, A.P. Survival, persistence, and isolation of the emerging multidrug-resistant pathogenic yeast Candida auris on a plastic health care surface. J. Clin. Microbiol. 2017, 55, 2996-3005. [CrossRef] [PubMed]

63. Chowdhary, A.; Voss, A.; Meis, J.F. Multidrug-resistant Candida auris: 'new kid on the block' in hospital-associated infections? J. Hosp. Infect. 2016, 94, 209-212. [CrossRef] [PubMed]

64. Meis, J.F.; Chowdhary, A. Candida auris: a global fungal public health threat. Lancet Infect. Dis. 2018, 18, 1298-1299. [CrossRef]

65. Kathuria, S.; Singh, P.K.; Sharma, C.; Prakash, A.; Masih, A.; Kumar, A.; Meis, J.F.; Chowdhary, A. Multidrug-resistant Candida auris misidentified as Candida haemulonii: Characterization by matrix-assisted laser desorption ionization-time of flight mass spectrometry and DNA sequencing and its antifungal susceptibility profile variability by Vitek 2, CLSI broth microdilution, and Etest method. J. Clin. Microbiol. 2015, 53, 1823-1830. [PubMed]

66. Kumar, A.; Prakash, A.; Singh, A.; Kumar, H.; Hagen, F.; Meis, J.F.; Chowdhary, A. Candida haemulonii species complex: an emerging species in India and its genetic diversity assessed with multilocus sequence and amplified fragment-length polymorphism analyses. Emerg. Microbes Infect. 2016, 5, e49. [CrossRef] [PubMed]

67. Mizusawa, M.; Miller, H.; Green, R.; Lee, R.; Durante, M.; Perkins, R.; Hewitt, C.; Simner, P.J.; Carroll, K.C.; Hayden, R.T.; et al. Can multidrug-resistant Candida auris be reliably identified in clinical microbiology laboratories? J. Clin. Microbiol. 2017, 55, 638-640. [CrossRef] [PubMed]

68. Prakash, A.; Sharma, C.; Singh, A.; Kumar Singh, P.; Kumar, A.; Hagen, F.; Govender, N.P.; Colombo, A.L.; Meis, J.F.; Chowdhary, A. Evidence of genotypic diversity among Candida auris isolates by multilocus sequence typing, matrix-assisted laser desorption ionization time-of-flight mass spectrometry and amplified fragment length polymorphism. Clin. Microbiol. Infect. 2016, 22, e271-e279. [CrossRef]

69. Arendrup, M.C.; Prakash, A.; Meletiadis, J.; Sharma, C.; Chowdhary, A. Comparison of EUCAST and CLSI reference microdilution MICs of eight antifungal compounds for Candida auris and associated tentative epidemiological cutoff values. Antimicrob. Agents Chemother. 2017, 61. [CrossRef]

70. Hyde, K.D.; Al-Hatmi, A.M.S.; Andersen, B.; Boekhout, T.; Buzina, W.; Dawson, T.L.; Eastwood, D.C.; Jones, E.B.G.; de Hoog, S.; Kang, Y.; et al. The world's ten most feared fungi. Fungal Diversity 2018. [CrossRef]

71. Larkin, E.; Hager, C.; Chandra, J.; Mukherjee, P.K.; Retuerto, M.; Salem, I.; Long, L.; Isham, N.; Kovanda, L.; Borroto-Esoda, K.; et al. The emerging pathogen Candida auris: Growth phenotype, virulence factors, activity of antifungals, and effect of SCY-078, a novel glucan synthesis inhibitor, on growth morphology and biofilm formation. Antimicrob. Agents Chemother. 2017, 61. [CrossRef]

72. Hager, C.L.; Larkin, E.L.; Long, L.A.; Ghannoum, M.A. Evaluation of the efficacy of rezafungin, a novel echinocandin, in the treatment of disseminated Candida auris infection using an immunocompromised mouse model. J. Antimicrob. Chemother. 2018, 73, 2085-2088. [CrossRef]

73. Hager, C.L.; Larkin, E.L.; Long, L.; Zohra Abidi, F.; Shaw, K.J.; Ghannoum, M.A. In vitro and in vivo evaluation of the antifungal activity of APX001A/APX001 against Candida auris. Antimicrob. Agents Chemother. 2018, 62. [CrossRef] [PubMed]

74. Fakhim, H.; Vaezi, A.; Dannaoui, E.; Chowdhary, A.; Nasiry, D.; Faeli, L.; Meis, J.F.; Badali, H. Comparative virulence of Candida auris with Candida haemulonii, Candida glabrata and Candida albicans in a murine model. Mycoses 2018, 61, 377-382. [CrossRef] [PubMed]

75. Adams, E.; Quinn, M.; Tsay, S.; Poirot, E.; Chaturvedi, S.; Southwick, K.; Greenko, J.; Fernandez, R.; Kallen, A.; Vallabhaneni, S.; et al. Candida auris in Healthcare Facilities, New York, USA, 2013-2017. Emerg. Infect. Dis. 2018, 24, 1816-1824. [CrossRef] [PubMed]

76. Chatterjee, S.; Alampalli, S.V.; Nageshan, R.K.; Chettiar, S.T.; Joshi, S.; Tatu, U.S. Draft genome of a commonly misdiagnosed multidrug resistant pathogen Candida auris. BMC Genomics 2015, 16, 686. [CrossRef] [PubMed] 
77. Healey, K.R.; Kordalewska, M.; Jimenez Ortigosa, C.; Singh, A.; Berrio, I.; Chowdhary, A.; Perlin, D.S. Limited ERG11 mutations identified in isolates of Candida auris directly contribute to reduced azole susceptibility. Antimicrob. Agents Chemother. 2018, 62, e01427-18. [CrossRef] [PubMed]

78. Lepak, A.J.; Zhao, M.; Berkow, E.L.; Lockhart, S.R.; Andes, D.R. Pharmacodynamic optimization for treatment of invasive Candida auris infection. Antimicrob. Agents Chemother. 2017, 61. [CrossRef] [PubMed]

79. Fakhim, H.; Chowdhary, A.; Prakash, A.; Vaezi, A.; Dannaoui, E.; Meis, J.F.; Badali, H. In vitro interactions of echinocandins with triazoles against multidrug-resistant Candida auris. Antimicrob. Agents Chemother. 2017, 61. [CrossRef]

80. Kordalewska, M.; Lee, A.; Park, S.; Berrio, I.; Chowdhary, A.; Zhao, Y.; Perlin, D.S. Understanding echinocandin resistance in the emerging pathogen Candida auris. Antimicrob. Agents Chemother. 2018, 62. [CrossRef]

81. Arendrup, M.C.; Chowdhary, A.; Astvad, K.M.T.; Jorgensen, K.M. APX001A in vitro activity against contemporary blood isolates and Candida auris determined by the EUCAST reference method. Antimicrob. Agents Chemother. 2018, 62. [CrossRef]

82. Berkow, E.L.; Angulo, D.; Lockhart, S.R. In vitro activity of a novel glucan synthase inhibitor, SCY-078, against clinical isolates of Candida auris. Antimicrob. Agents Chemother. 2017, 61. [CrossRef] [PubMed]

83. Berkow, E.L.; Lockhart, S.R. Activity of novel antifungal compound APX001A against a large collection of Candida auris. J. Antimicrob. Chemother. 2018, 73, 3060-3062. [CrossRef] [PubMed]

84. Berkow, E.L.; Lockhart, S.R. Activity of CD101, a long-acting echinocandin, against clinical isolates of Candida auris. Diagn Microbiol. Infect. Dis. 2018, 90, 196-197. [CrossRef] [PubMed]

85. Lepak, A.J.; Zhao, M.; Andes, D.R. Pharmacodynamic evaluation of rezafungin (CD101) against Candida auris in the neutropenic mouse invasive candidiasis model. Antimicrob. Agents Chemother. 2018, 62. [CrossRef] [PubMed]

86. Wiederhold, N.P.; Patterson, H.P.; Tran, B.H.; Yates, C.M.; Schotzinger, R.J.; Garvey, E.P. Fungal-specific Cyp51 inhibitor VT-1598 demonstrates in vitro activity against Candida and Cryptococcus species, endemic fungi, including Coccidioides species, Aspergillus species and Rhizopus arrhizus. J. Antimicrob. Chemother. 2018, 73, 404-408. [CrossRef] [PubMed]

87. Break, T.J.; Desai, J.V.; Healey, K.R.; Natarajan, M.; Ferre, E.M.N.; Henderson, C.; Zelazny, A.; Siebenlist, U.; Yates, C.M.; Cohen, O.J.; et al. VT-1598 inhibits the in vitro growth of mucosal Candida strains and protects against fluconazole-susceptible and -resistant oral candidiasis in IL-17 signalling-deficient mice. J. Antimicrob. Chemother. 2018, 73, 2089-2094. [CrossRef] [PubMed]

88. Ku, T.S.N.; Walraven, C.J.; Lee, S.A. Candida auris: Disinfectants and implications for infection control. Front. Microbiol. 2018, 9, 726. [CrossRef]

89. Moore, G.; Schelenz, S.; Borman, A.M.; Johnson, E.M.; Brown, C.S. Yeasticidal activity of chemical disinfectants and antiseptics against Candida auris. J. Hosp. Infect. 2017, 97, 371-375. [CrossRef] [PubMed]

90. Abdolrasouli, A.; Armstrong-James, D.; Ryan, L.; Schelenz, S. In vitro efficacy of disinfectants utilised for skin decolonisation and environmental decontamination during a hospital outbreak with Candida auris. Mycoses 2017, 60, 758-763. [CrossRef]

91. Denning, D.W.; Venkateswarlu, K.; Oakley, K.L.; Anderson, M.J.; Manning, N.J.; Stevens, D.A.; Warnock, D.W.; Kelly, S.L. Itraconazole resistance in Aspergillus fumigatus. Antimicrob. Agents Chemother. 1997, 41, 1364-1368. [CrossRef]

92. Verweij, P.E.; Chowdhary, A.; Melchers, W.J.; Meis, J.F. Azole resistance in Aspergillus fumigatus: Can we retain the clinical use of mold-active antifungal azoles? Clin. Infect. Dis. 2016, 62, 362-368. [CrossRef] [PubMed]

93. Denning, D.W.; Perlin, D.S. Azole resistance in Aspergillus: a growing public health menace. Future Microbiol. 2011, 6, 1229-1232. [CrossRef] [PubMed]

94. van der Linden, J.W.; Arendrup, M.C.; Warris, A.; Lagrou, K.; Pelloux, H.; Hauser, P.M.; Chryssanthou, E.; Mellado, E.; Kidd, S.E.; Tortorano, A.M.; et al. Prospective multicenter international surveillance of azole resistance in Aspergillus fumigatus. Emerg. Infect. Dis. 2015, 21, 1041-1044. [CrossRef] [PubMed]

95. Meis, J.F.; Chowdhary, A.; Rhodes, J.L.; Fisher, M.C.; Verweij, P.E. Clinical implications of globally emerging azole resistance in Aspergillus fumigatus. Philos Trans. R Soc. Lond B Biol. Sci. 2016, 371. [CrossRef] [PubMed]

96. Goncalves, S.S.; Souza, A.C.; Chowdhary, A.; Meis, J.F.; Colombo, A.L. Epidemiology and molecular mechanisms of antifungal resistance in Candida and Aspergillus. Mycoses 2016. [CrossRef] 
97. Mortensen, K.L.; Mellado, E.; Lass-Florl, C.; Rodriguez-Tudela, J.L.; Johansen, H.K.; Arendrup, M.C. Environmental study of azole-resistant Aspergillus fumigatus and other aspergilli in Austria, Denmark, and Spain. Antimicrob. Agents Chemother. 2010, 54, 4545-4549. [CrossRef] [PubMed]

98. Snelders, E.; Huis In 't Veld, R.A.; Rijs, A.J.; Kema, G.H.; Melchers, W.J.; Verweij, P.E. Possible environmental origin of resistance of Aspergillus fumigatus to medical triazoles. Appl. Environ. Microbiol. 2009, 75, 4053-4057. [CrossRef]

99. Badali, H.; Vaezi, A.; Haghani, I.; Yazdanparast, S.A.; Hedayati, M.T.; Mousavi, B.; Ansari, S.; Hagen, F.; Meis, J.F.; Chowdhary, A. Environmental study of azole-resistant Aspergillus fumigatus with TR34/L98H mutations in the cyp51A gene in Iran. Mycoses 2013, 56, 659-663. [CrossRef]

100. Ozmerdiven, G.E.; Ak, S.; Ener, B.; Agca, H.; Cilo, B.D.; Tunca, B.; Akalin, H. First determination of azole resistance in Aspergillus fumigatus strains carrying the TR34/L98H mutations in Turkey. J. Infect. Chemother. 2015, 21, 581-586. [CrossRef]

101. Koehler, P.; Hamprecht, A.; Bader, O.; Bekeredjian-Ding, I.; Buchheidt, D.; Doelken, G.; Elias, J.; Haase, G.; Hahn-Ast, C.; Karthaus, M.; et al. Epidemiology of invasive aspergillosis and azole resistance in patients with acute leukaemia: the SEPIA Study. Int J. Antimicrob. Agents 2017, 49, 218-223. [CrossRef]

102. Resendiz Sharpe, A.; Lagrou, K.; Meis, J.F.; Chowdhary, A.; Lockhart, S.R.; Verweij, P.E.; ISHAM ECMM Aspergillus Resistance Surveillance Working Group. Triazole resistance surveillance in Aspergillus fumigatus. Med. Mycol. 2018, 56, 83-92. [CrossRef]

103. CLSI. CLSI Document M38-A2. Reference Method for Broth Dilution Antifungal Susceptibility Testing of Filamentous Fungi; Approved Standard-Second Edition; Clinical and Laboratory Standards Institute: Wayne, PA, USA, 2008.

104. Arendrup, M.C.; Meletiadis, J.; Mouton, J.W.; Lagrou, K.; Hamal, P.; Guinea, J.; Subcommittee on AFST of the ESCMID for EUCAST. EUCAST Definitive Document E.DEF 9.3.1 Method for the Determination of Broth Dilution Minimum Inhibitory Concentrations of Antifungal Agents for Conidia Forming Moulds. Available online: http://www.eucast.org/ast_of_fungi/methodsinantifungalsusceptibilitytesting/susceptibility_ testing_of_moulds/ (accessed on 1 November 2018).

105. Meletiadis, J.; Leth Mortensen, K.; Verweij, P.E.; Mouton, J.W.; Arendrup, M.C. Spectrophotometric reading of EUCAST antifungal susceptibility testing of Aspergillus fumigatus. Clin. Microbiol. Infect. 2017, 23, 98-103. [CrossRef] [PubMed]

106. Ullmann, A.J.; Aguado, J.M.; Arikan-Akdagli, S.; Denning, D.W.; Groll, A.H.; Lagrou, K.; Lass-Flörl, C.; Lewis, R.E.; Munoz, P.; Verweij, P.E.; et al. Diagnosis and management of Aspergillus diseases: executive summary of the 2017 ESCMID-ECMM-ERS guideline. Clin. Microbiol. Infect. 2018, 24, e1-e38. [CrossRef] [PubMed]

107. Patterson, T.F.; Thompson, G.R., 3rd; Denning, D.W.; Fishman, J.A.; Hadley, S.; Herbrecht, R.; Kontoyiannis, D.P.; Marr, K.A.; Morrison, V.A.; Nguyen, M.H.; et al. Practice guidelines for the diagnosis and management of aspergillosis: 2016 Update by the Infectious Diseases Society of America. Clin. Infect. Dis. 2016, 63, e1-e60. [CrossRef] [PubMed]

108. CLSI. CLSI Document M51-A. Method for Antifungal Disk Diffusion Susceptibility Testing of Nondermatophyte Filamentous Fungi; Approved Guideline; Clinical and Laboratory Standards Institute: Wayne, PA, USA, 2010.

109. Espinel-Ingroff, A.; Chowdhary, A.; Gonzalez, G.M.; Lass-Florl, C.; Martin-Mazuelos, E.; Meis, J.; Pelaez, T.; Pfaller, M.A.; Turnidge, J. Multicenter study of isavuconazole MIC distributions and epidemiological cutoff values for Aspergillus spp. for the CLSI M38-A2 broth microdilution method. Antimicrob. Agents Chemother. 2013, 57, 3823-3828. [CrossRef] [PubMed]

110. Espinel-Ingroff, A.; Cuenca-Estrella, M.; Fothergill, A.; Fuller, J.; Ghannoum, M.; Johnson, E.; Pelaez, T.; Pfaller, M.A.; Turnidge, J. Wild-type MIC distributions and epidemiological cutoff values for amphotericin B and Aspergillus spp. for the CLSI broth microdilution method (M38-A2 document). Antimicrob. Agents Chemother. 2011, 55, 5150-5154. [CrossRef]

111. Espinel-Ingroff, A.; Diekema, D.J.; Fothergill, A.; Johnson, E.; Pelaez, T.; Pfaller, M.A.; Rinaldi, M.G.; Canton, E.; Turnidge, J. Wild-type MIC distributions and epidemiological cutoff values for the triazoles and six Aspergillus spp. for the CLSI broth microdilution method (M38-A2 document). J. Clin. Microbiol. 2010, 48, 3251-3257. [CrossRef]

112. CLSI. CLSI Document M59. Epidemiological Cutoff Values for Antifungal Susceptibility Testing, 1st ed.; Clinical and Laboratory Standards Institute: Wayne, PA, USA, 2016.

113. EUCAST. Available online: http:/ / www.eucast.org/ (accessed on 1 November 2018). 
114. Arendrup, M.C.; Verweij, P.E.; Mouton, J.W.; Lagrou, K.; Meletiadis, J. Multicentre validation of 4-well azole agar plates as a screening method for detection of clinically relevant azole-resistant Aspergillus fumigatus. J. Antimicrob. Chemother. 2017, 72, 3325-3333. [CrossRef]

115. Guinea, J.; Verweij, P.E.; Meletiadis, J.; Mouton, J.W.; Barchiesi, F.; Arendrup, M.C.; Subcommittee on Antifungal Susceptibility Testing of the ESCMID European Committee for Antimicrobial Susceptibility Testing (EUCAST), EUCAST-AFST; Arendrup, M.C.; Arikan-Akdagli, S.; Barchiesi, F.; et al. How to: EUCAST recommendations on the screening procedure E.Def 10.1 for the detection of azole resistance in Aspergillus fumigatus isolates using four well azole-containing agar plates. Clin. Microbiol. Infect. 2018. [CrossRef]

116. Chowdhary, A.; Sharma, C.; Meis, J.F. Azole-resistant aspergillosis: Epidemiology, molecular mechanisms, and treatment. J. Infect. Dis. 2017, 216, S436-S444. [CrossRef]

117. Alvarez-Moreno, C.; Lavergne, R.A.; Hagen, F.; Morio, F.; Meis, J.F.; Le Pape, P. Azole-resistant Aspergillus fumigatus harboring TR34/L98H, TR46/Y121F/T289A and TR53 mutations related to flower fields in Colombia. Sci Rep. 2017, 7, 45631. [CrossRef] [PubMed]

118. Hodiamont, C.J.; Dolman, K.M.; Ten Berge, I.J.; Melchers, W.J.; Verweij, P.E.; Pajkrt, D. Multiple-azole-resistant Aspergillus fumigatus osteomyelitis in a patient with chronic granulomatous disease successfully treated with long-term oral posaconazole and surgery. Med. Mycol. 2009, 47, 217-220. [CrossRef] [PubMed]

119. Abdolrasouli, A.; Rhodes, J.; Beale, M.A.; Hagen, F.; Rogers, T.R.; Chowdhary, A.; Meis, J.F.; Armstrong-James, D.; Fisher, M.C. Genomic context of azole resistance mutations in Aspergillus fumigatus determined using whole-genome sequencing. MBio 2015, 6, e00536. [CrossRef]

120. Deng, S.; Zhang, L.; Ji, Y.; Verweij, P.E.; Tsui, K.M.; Hagen, F.; Houbraken, J.; Meis, J.F.; Abliz, P.; Wang, X.; et al. Triazole phenotypes and genotypic characterization of clinical Aspergillus fumigatus isolates in China. Emerg. Microbes Infect. 2017, 6, e109. [CrossRef] [PubMed]

121. Snelders, E.; van der Lee, H.A.; Kuijpers, J.; Rijs, A.J.; Varga, J.; Samson, R.A.; Mellado, E.; Donders, A.R.; Melchers, W.J.; Verweij, P.E. Emergence of azole resistance in Aspergillus fumigatus and spread of a single resistance mechanism. PLoS Med. 2008, 5, e219. [CrossRef] [PubMed]

122. van der Linden, J.W.; Snelders, E.; Kampinga, G.A.; Rijnders, B.J.; Mattsson, E.; Debets-Ossenkopp, Y.J.; Kuijper, E.J.; Van Tiel, F.H.; Melchers, W.J.; Verweij, P.E. Clinical implications of azole resistance in Aspergillus fumigatus, The Netherlands, 2007-2009. Emerg. Infect. Dis. 2011, 17, 1846-1854. [CrossRef] [PubMed]

123. Lestrade, P.P.; Bentvelsen, R.G.; Schauwvlieghe, A.; Schalekamp, S.; van der Velden, W.; Kuiper, E.J.; van Paassen, J.; van der Hoven, B.; van der Lee, H.A.; Melchers, W.J.G.; et al. Voriconazole resistance and mortality in invasive aspergillosis: A multicenter retrospective cohort study. Clin. Infect. Dis. 2018. [CrossRef]

124. Chong, G.M.; van der Beek, M.T.; von dem Borne, P.A.; Boelens, J.; Steel, E.; Kampinga, G.A.; Span, L.F.; Lagrou, K.; Maertens, J.A.; Dingemans, G.J.; et al. PCR-based detection of Aspergillus fumigatus Cyp51A mutations on bronchoalveolar lavage: a multicentre validation of the AsperGenius assay(R) in 201 patients with haematological disease suspected for invasive aspergillosis. J. Antimicrob. Chemother. 2016, 71, 3528-3535. [CrossRef]

125. Heo, S.T.; Tatara, A.M.; Jimenez-Ortigosa, C.; Jiang, Y.; Lewis, R.E.; Tarrand, J.; Tverdek, F.; Albert, N.D.; Verweij, P.E.; Meis, J.F.; et al. Changes in in vitro susceptibility patterns of Aspergillus to triazoles and correlation with aspergillosis outcome in a tertiary care cancer center, 1999-2015. Clin. Infect. Dis. 2017, 65, 216-225. [CrossRef]

126. Verweij, P.E.; Ananda-Rajah, M.; Andes, D.; Arendrup, M.C.; Bruggemann, R.J.; Chowdhary, A.; Cornely, O.A.; Denning, D.W.; Groll, A.H.; Izumikawa, K.; et al. International expert opinion on the management of infection caused by azole-resistant Aspergillus fumigatus. Drug Resist. Updates 2015, 21-22, 30-40. [CrossRef]

(C) 2018 by the authors. Licensee MDPI, Basel, Switzerland. This article is an open access article distributed under the terms and conditions of the Creative Commons Attribution (CC BY) license (http:/ / creativecommons.org/licenses/by/4.0/). 